\title{
Varicella-zoster virus glycoprotein expression differentially induces the unfolded protein response in infected cells
}

\author{
John E. Carpenter and Charles Grose* \\ Virology Laboratory, Department of Infectious Diseases, University of lowa Children's Hospital, lowa City, IA, USA
}

\section{Edited by:}

Shiu-Wan Chan, The University of

Manchester, UK

\section{Reviewed by:}

Aaron T. Irving, National University of Singapore, Singapore

Carolyn Machamer, Johns Hopkins School of Medicine, USA

Maria Guadalupe Vizoso Pinto, Max von Pettenkofer Institute of the Ludwig Maximilian University of Munich, Germany

Naoki Inoue, Gifu Pharmaceutical

University, Japan

*Correspondence:

Charles Grose, Department of

Pediatrics, University of lowa

Hospital, 200 Hawkins Drive, lowa

City, IA 52242, USA

e-mail: charles-grose@uiowa.edu
Varicella-zoster virus (VZV) is a human herpesvirus that spreads to children as varicella or chicken pox. The virus then establishes latency in the nervous system and re-emerges, typically decades later, as zoster or shingles. We have reported previously that VZV induces autophagy in infected cells as well as exhibiting evidence of the Unfolded Protein Response (UPR): XBP1 splicing, a greatly expanded Endoplasmic Reticulum (ER) and $\mathrm{CHOP}$ expression. Herein we report the results of a UPR specific PCR array that measures the levels of mRNA of 84 different components of the UPR in VZV infected cells as compared to tunicamycin treated cells as a positive control and uninfected, untreated cells as a negative control. Tunicamycin is a mixture of chemicals that inhibits N-linked glycosylation in the ER with resultant protein misfolding and the UPR. We found that VZV differentially induces the UPR when compared to tunicamycin treatment. For example, tunicamycin treatment moderately increased (8-fold) roughly half of the array elements while downregulating only three (one ERAD and two FOLD components). VZV infection on the other hand upregulated 33 components including a little described stress sensor CREB-H (64-fold) as well as ER membrane components INSIG and gp78, which modulate cholesterol synthesis while downregulating over 20 components mostly associated with ERAD and FOLD. We hypothesize that this expression pattern is associated with an expanding ER with downregulation of active degradation by ERAD and apoptosis as the cell attempts to handle abundant viral glycoprotein synthesis.

Keywords: herpesvirus, unfolded protein response, autophagy, tunicamycin, ERAD, CREBH, gp78, INSIG

\section{INTRODUCTION}

VZV is a human pathogen that spreads to children as varicella or chicken pox and re-emerges later as zoster or shingles (Ross, 1962; Grose, 1981). VZV is one of nine human herpesviruses (Davison, 2010). The virus is supremely adapted to its human host and infects most people in a given community (Hope-Simpson, 1965; Choo et al., 1995). It is endemic throughout the world but largely controlled in some countries by vaccination with a live attenuated virus (Seward et al., 2008; Marin et al., 2011).

Varicella infection, within its natural human host, spreads from the nasopharynx via infection of a limited number of $\mathrm{T}$ cells that home to the skin epidermis (Arvin et al., 2010). Once there the infection is passed to the basal keratinocytes making up the innermost layer of the epidermis (Ku et al., 2004). The virus progressively infects other cells in its proximity until reaching the surface of the skin in the form of characteristic VZV vesicles. Within the area of the vesicle, polykaryocytes or multi-nucleated cells are found due to VZV-induced cell to cell fusion (Weigle and Grose, 1984). As the number of viral particles increase within the vesicle, some particles travel retrograde along sensory neurons in the skin to the sensory ganglia emanating from the spinal cord (Gilden et al., 2003). In the ganglia, the virus becomes latent or quiescent until much later (years or decades) in the life of the host. Under conditions of immunosuppression or aging, VZV can reactivate within the ganglia and spread back anterograde to the skin to cause zoster or shingles (Arvin, 1987). Typically, this event only happens from a single ganglion within one dermatome (Hope-Simpson, 1965).

VZV is an alphaherpesvirus that exists as a multilayered structure approximately $200 \mathrm{~nm}$ in diameter (Grose et al., 1983). In the virus particle, the genome (dsDNA) is surrounded by a protein capsid structure that is covered by an amorphous layer of tegument proteins. These two structures are surrounded by a lipid envelope that contains viral glycoproteins. The VZV genome is the smallest of the human herpesviruses and encodes at least 71 unique proteins (ORF0-ORF68) with three more opening reading frames (ORF69-ORF71) that duplicate earlier open reading frames (ORF64-62, respectively) (Davison and Scott, 1986). Only a fraction of the encoded proteins form the structure of the virus particle (Kinchington et al., 1992). Among those proteins are nine glycoproteins: ORF5 (gK), ORF9A (gN), ORF14 (gC), ORF31 (gB), ORF37 (gH), ORF50 (gM), ORF60 (gL), ORF67 (gI), and ORF68 (gE). Abundant biosynthesis of viral glycoproteins increases to the point of excluding cellular glycoprotein expression under conditions of infection in cultured cells (Grose, 1980).

Of importance, VZV induces autophagy in infected cells as well as exhibiting evidence of the Unfolded Protein Response (UPR): XBP1 splicing and a greatly expanded ER (Takahashi et al., 2009; Carpenter et al., 2011). More recently, we 
found that inhibition of autophagy by either 3-methyl adenine (3-MA) treatment or siRNA knockdown of ATG-5, a necessary autophagy protein, reduced glycoprotein expression and altered post-translational modifications of VZV gE and gI and ultimately VZV infectivity in culture. (Buckingham et al., 2014). These results highlight the role of VZV glycoprotein expression in inducing ER stress and associated autophagy. Our observations of enlarged ER and spliced XBP-1 in VZV infected cells led us to consider what other elements of the UPR are being activated. We decided to use a commercial PCR array that measures the levels of transcripts of 84 different components of the UPR. Herein we report the results of comparing VZV infected cells vs. tunicamycin treated cells with this UPR PCR array.

\section{METHODS \\ VIRUSES AND CELLS}

VZV-32 is a low passage laboratory strain; its genome has been completely sequenced and falls within European clade 1 of VZV genotypes (Peters et al., 2006). MRC-5 human fibroblast cells or HeLa cells were grown in six well tissue culture plates with and without $12 \mathrm{~mm}$ round or $22 \mathrm{~mm}$ square coverslips in Minimum Essential Medium (MEM; Gibco, Life Technologies) supplemented with 7\% fetal bovine serum (FBS), L-glutamine, non-essential amino acids, and penicillin/streptomycin. When monolayers were nearly confluent, MRC-5 cells were inoculated with VZV-infected cells at a ratio of one infected cell to eight uninfected cells by previously described methods (Grose and Brunel, 1978).

\section{TRANSFECTION}

HeLa cells were transfected with plasmids containing VZV gE (pTargeT_gE) or VZV ORF62 (pCMV_IE62) under the CMV promoter as described previously (Carpenter et al., 2011). The plasmids were transfected into HeLa cells using ExtremeGene HP (Roche) transfection reagent (Jacobsen et al., 2004) at $10 \mu \mathrm{l} / \mathrm{ml}$ and plasmid DNA at a concentration of $1.0 \mu \mathrm{g} / \mathrm{ml}$. After $6 \mathrm{~h}$, the culture medium was replaced with plas$\mathrm{mid} /$ transfection reagent free medium. At $24 \mathrm{~h}$ post-transfection, RNA was extracted from all wells in a culture plate and cells incubated on coverslips were fixed and processed for microscopy.

\section{REAL-TIME RT-PCR}

Total RNA was extracted from uninfected, tunicamycin treated and VZV infected fibroblast cells in six well plates at the given time points using the RNEasy mini kit (Qiagen). RNA quality and quantity was assayed by UV spectroscopy using a NanoDrop spectrometer. Both A260/A280 and A260/A230 ratios were within $20 \%$ of 2.0 and infected cells from a six well plate well $(6.5 \mathrm{sq} \mathrm{cm})$ yielded approximately $3 \mu \mathrm{g}$ of RNA in $60 \mu \mathrm{l}$. Further, the RNA was electrophoresed in an Agilent Bioanalyzer 2100 (Agilent) and yielded RIN values within $20 \%$ of 10 . Polyadenylated RNA was converted to cDNA using anchored Oligo(dT) primers and the SuperScript III First-Strand Synthesis System for RT-PCR (Invitrogen) to yield approximately $20 \mathrm{ng}$ of cDNA. The entire cDNA sample from one well of cells was mixed into $1 \mathrm{ml}$ of $1 \times$ diluted Power SYBR Green Master Mix (ABI) and split into all wells of a SA Biosciences UPR PCR array (Life Technologies) with a multichannel pipettor $(25 \mu l$ per well). The measurements were carried out in triplicate using cDNA from three of the original six wells in the plate for all types of samples using a Model 7000 real time PCR instrument (ABI). The resulting PCR results were processed using the SDS 1.2.3 software (Applied Biosystems). $\mathrm{C}_{\mathrm{T}}$ values of each measurement were normalized to an average of 16.0 for housekeeping genes (wells H1-H5 of the UPR array) to form $\Delta C_{T}$ values which were then used to calculate averages and standard deviations between triplicate measurements. Subsequent $\Delta \Delta \mathrm{C}_{\mathrm{T}}$ values were calculated by differences between averages of VZV infected $\Delta \mathrm{C}_{\mathrm{T}}$ values or tunicamycin treated $\Delta C_{T}$ values with the average uninfected $\Delta C_{T}$ values. Uncertainties correspond to propagation of errors using standard deviations between the uninfected and infected or tunicamycin averages.

\section{RT-PCR PRIMERS}

To confirm measurements from the UPR specific PCR array, several RT-PCR measurements were carried out using the following primers: BiP: forward 5'-CCC CAA CTG GTG AAG AGG AT- $3^{\prime}$ and reverse $5^{\prime}$-GCA GTA AAC AGC CGC TTA GG-3'; DNAJB9/ERDj4: forward 5'-ACA TCT GTG ACT TGC GTT GC$3^{\prime}$ and reverse $5^{\prime}$-TGG GCA ATA AAA CCA TTT CC-3'; CREBH: forward 5'-GGG AGA CGA GCT GTG AGC-3' and reverse 5'TGT CTG AGT GTC GGT TCC TG-3'; PERK: forward 5'-GCC TAA GGA GGT AGC AGC AA- $3^{\prime}$ and reverse $5^{\prime}$-GGG ACA AAA ATG GAG TCA GC-3'.

\section{ANTIBODIES}

Murine MAb antibodies to VZV gE (3B3) and IE62 (5C6) produced in our laboratory were used in addition to a rabbit polyclonal antibody to LC3B (Santa Cruz Biotech sc-28266).

\section{IMAGING PROTOCOLS}

Samples of infected and uninfected cells were prepared for confocal microscopy by methods described previously (Carpenter et al., 2008). Briefly, the samples were fixed with paraformaldehyde and permabilized with $0.05 \%$ Triton-X-100 in PBS and then blocked in 5\% non-fat milk with $2.5 \%$ normal goat serum for $2 \mathrm{~h}$ at RT. The primary antibody (1:2000) was added for $2 \mathrm{~h}$ at RT and overnight at $4^{\circ} \mathrm{C}$. After washing $(3 \times 5 \mathrm{~min}$ with PBS $)$ the samples were incubated with the secondary antibody (1:1250) and the Hoechst 33342 dsDNA stain (1:500) for $2 \mathrm{~h}$ at RT then washed before mounting on slides for viewing. Following preparation, the samples were viewed on a Zeiss 710 confocal fluorescent microscope (Duus et al., 1995).

\section{TUNICAMYCIN PROTOCOL}

Conditions for treatment of cultured cells with tunicamycin $(2.5 \mu \mathrm{g} / \mathrm{ml}$; Calbiochem, \#654380) have been described in earlier papers in which we were investigating VZV glycoprotein biosynthesis (Montalvo et al., 1985; Carpenter et al., 2010). For experiments in uninfected cells, tunicamycin $(2.5 \mu \mathrm{g} / \mathrm{ml})$ was added $24 \mathrm{~h}$ after subculturing and the monolayer was fixed after another $24 \mathrm{~h}$. 


\section{ER LABELING BY DICARBOCYANINE DYE}

DiOC $_{6}$ (3-3-dihexyloxa-carbocyanine iodide) was obtained in powder form from Molecular Probes (D-273) and dissolved $(0.7 \mathrm{mg} / \mathrm{ml})$ in ethanol (Sabnis et al., 1997). An aliquot of the $\mathrm{DiOC}_{6}$ stock $\left(2.8 \mu \mathrm{l} / \mathrm{ml}\right.$ yielded a final concentration of $\mathrm{DiOC}_{6}$ of $2 \mu \mathrm{g} / \mathrm{ml}$ ) was added to warm cell culture medium; this medium was applied to live cells for $30 \mathrm{~min}$, then rinsed $2 \times$ with PBS and processed for fluorescent microscopy as described above.

\section{RESULTS}

\section{VZV INFECTED CELLS EXHIBITED ABUNDANT GLYCOPROTEIN} EXPRESSION WITH AN ENLARGED ER AND INCREASED AUTOPHAGY

Within cell culture, VZV is entirely cell associated with no release of cell-free virus (Grose and Brunel, 1978; Weller, 1983). Monolayers are inoculated with VZV-infected cells. The susceptibly of cells to VZV determines how long it takes to infect the whole monolayer but spread typically requires 3-5 days. Within infected cell monolayers, we observe a range of fused cells. For example, VZV induces massive syncytia involving hundreds of nuclei in melanoma cells while VZV infection of less fusogenic cells such as lung fibroblasts or skin keratinocytes induces syncytia involving tens of nuclei.

Recently, we observed that VZV induces increased LC3positive puncta formation indicative of autophagosomes within cultured cells as well as from cells removed from varicella and zoster vesicles (e.g., Figures 1A1,A2) (Takahashi et al., 2009). Unlike the closely related herpes simplex virus, VZV does not encode any known inhibitors of autophagy, such as ICP 34.5. Later we observed that VZV infected cells also exhibited signs of ER stress, namely XBP-1 splicing and a greatly enlarged ER (see, e.g., Figures 1B1,B2). The latter results led to the hypothesis that VZV glycoprotein synthesis induces ER stress that is partially relieved by an enlarging ER and increased autophagy (Carpenter et al., 2011).

\section{UPR GENE TRANSCRIPTION WAS DIFFERENT IN VZV INFECTED CELLS VS. TUNICAMYCIN TREATED CELLS}

Based on the observations in the previous section, we sought to further document the induction of the UPR within VZV infected cells via a UPR-specific PCR array manufactured by SA Biosciences (now part of Qiagen). This 96 well plate consists of 84 wells containing primers to the $3^{\prime}$ Untranslated Region (UTR) of transcripts associated with the UPR and the remaining 12 wells containing primers to housekeeping genes and PCR and cDNA quality control wells. Table 1 lists the UPR specific primers or wells where the wells are grouped by association with a given UPR function: ANTI or PRO (anti or pro-apoptotic), ERAD (ER associated degradation), FOLD (primarily folding chaperones), LIPID (transcripts associated with lipid synthesis and metabolism), SENSOR (transcripts associated with ER membrane resident proteins known to "sense" and signal ER stress conditions), TF (other transcription factors like $\mathrm{C} / \mathrm{EBP} \beta$ ) and finally TRANS for two components associated with protein translation. Each group will be described more fully in the next sections.

Gene transcripts were measured in uninfected human fibroblasts, tunicamycin (TM) treated fibroblasts and VZV infected
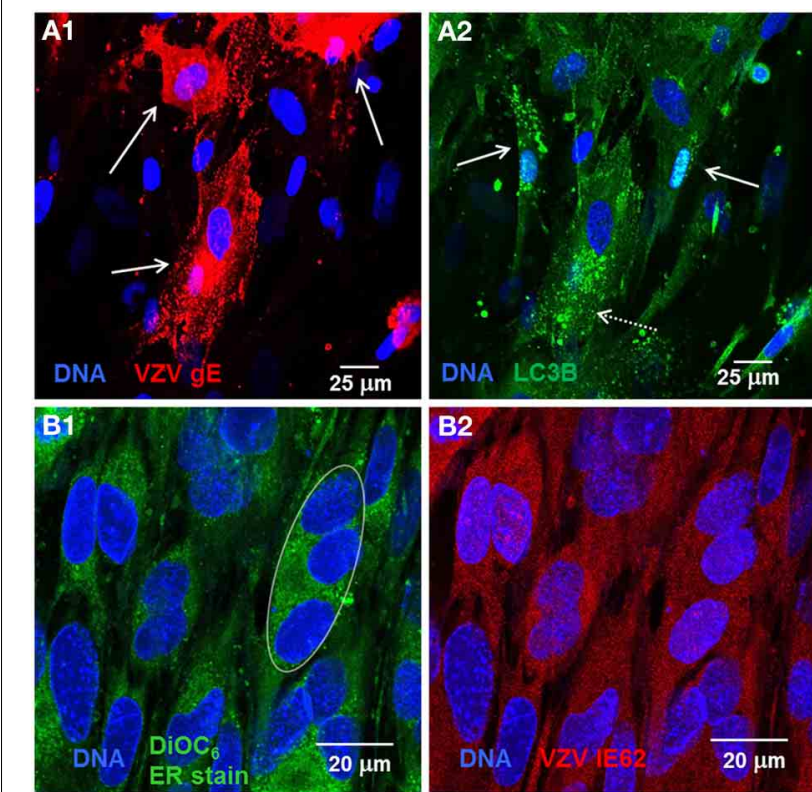

FIGURE 1 | VZV infected cells exhibited abundant glycoprotein expression, increased autophagosomes, and an enlarged ER. Human fibroblast cells (MRC-5) were grown on glass coverslips in tissue culture plates until $60 \%$ confluent and then infected with VZV-32 infected MRC-5 cells at a ratio of $1: 8$. At $48 \mathrm{hpi}$, the cultures were fixed, permeabilized, blocked and immunolabeled for VZV gE, IE62, or cellular LC3B. The cells were then imaged at $400 \times$ with a Zeiss 710 confocal fluorescence microscope. Other cultures grown and infected similarly were incubated in medium containing DiOC6, a polar dye, prior to fixation. (A1) VZV glycoprotein $\mathrm{gE}$ expression is abundant in three cells (solid arrows) in the image. (A2) LC3 puncta indicative of autophagosomes are apparent in cells expressing $\mathrm{gE}$ (arrows, dashed line) and nearby cells that are newly infected (arrows, solid line). (B1) $\mathrm{DiOC}_{6}$ staining in 19 cells at $630 \times$. A representative white ellipse indicates the enlarged $E R$ in an infected syncytium. (B2) VZV IE62 staining indicates that all 19 cells are infected and several are in syncytia.

fibroblasts. Each measurement was done in triplicate. The measured $\mathrm{C}_{\mathrm{T}}$ values were normalized so that in each case the housekeeping gene transcripts measured $\mathrm{C}_{\mathrm{T}}$ average was 16 and then the triplicate measurements were averaged and standard deviations computed to generate $\Delta \mathrm{C}_{\mathrm{T}}$. Differences between the uninfected $\Delta \mathrm{C}_{\mathrm{T}}$ and those associated with TM treated and VZV infected cell transcript measurements were then calculated to form the final measurements $\Delta \Delta \mathrm{C}_{\mathrm{T}}$ listed in Table 1. Graphs of the resulting values (Figure 2) showed that tunicamycin treatment, a classical ER stressor by inhibition of $\mathrm{N}$ glycosylation, upregulated 66 of the 84 UPR genes, with known folding chaperones, e.g., $\mathrm{BiP}$ (in blue), particularly upregulated. Also upregulated is the pro-apoptotic factor CHOP (pink). By contrast, only 43 of the UPR genes are upregulated in VZV infected cells. In particular, those genes most upregulated such as CREB3L3/CREBH (light blue) are more upregulated than after TM treatment. VZV infected cells also upregulated the LIPID transcripts $A M F R / g p 78$ and INSIG (green) while downregulating a number of ERAD components such as UBXN4/erasin and EDEM3 (red). These differences will be considered by group in the subsequent sections. 
Table 1 | UPR qPCR results for tunicamycin treated and VZV infected cells.

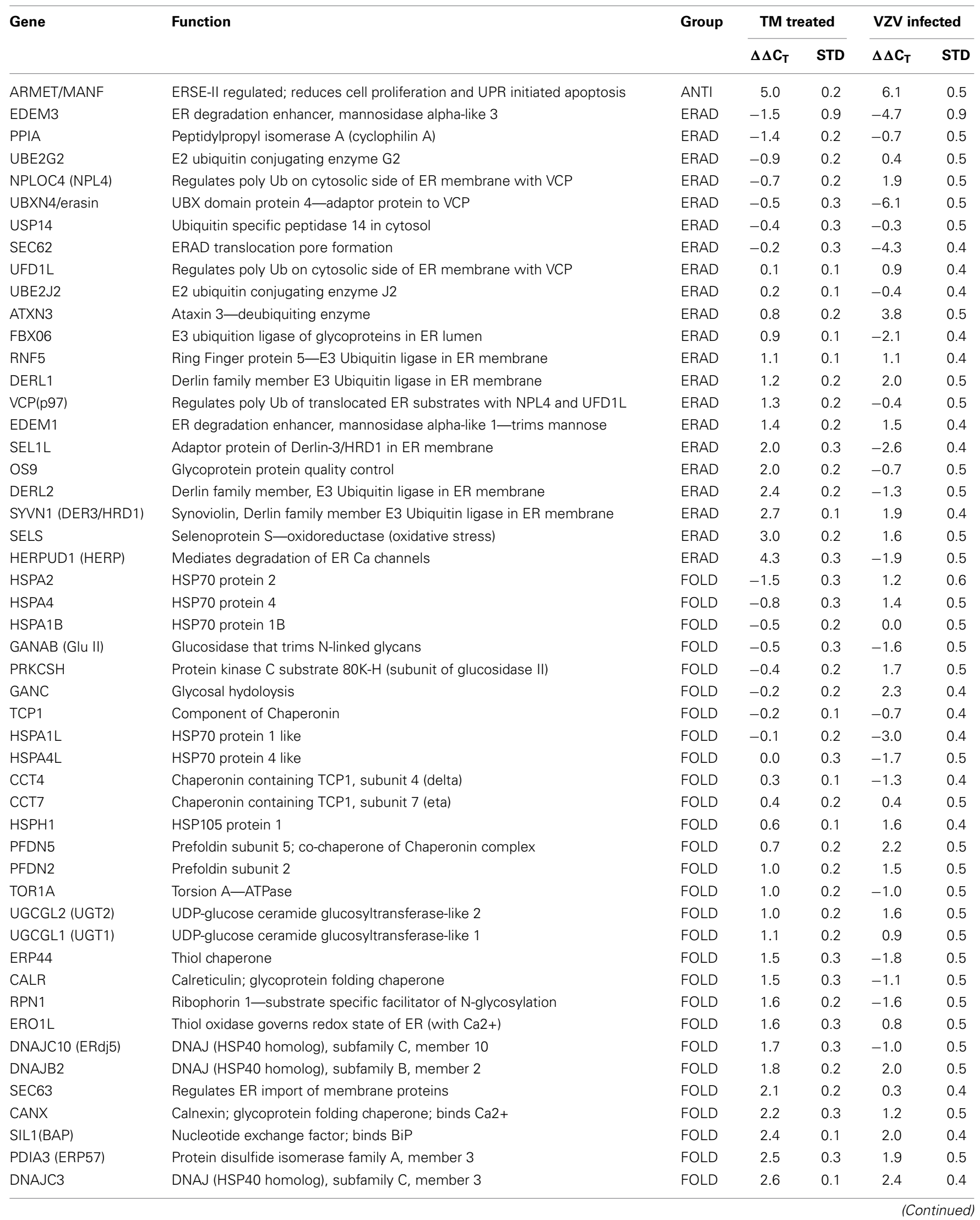


Table 1 | Continued

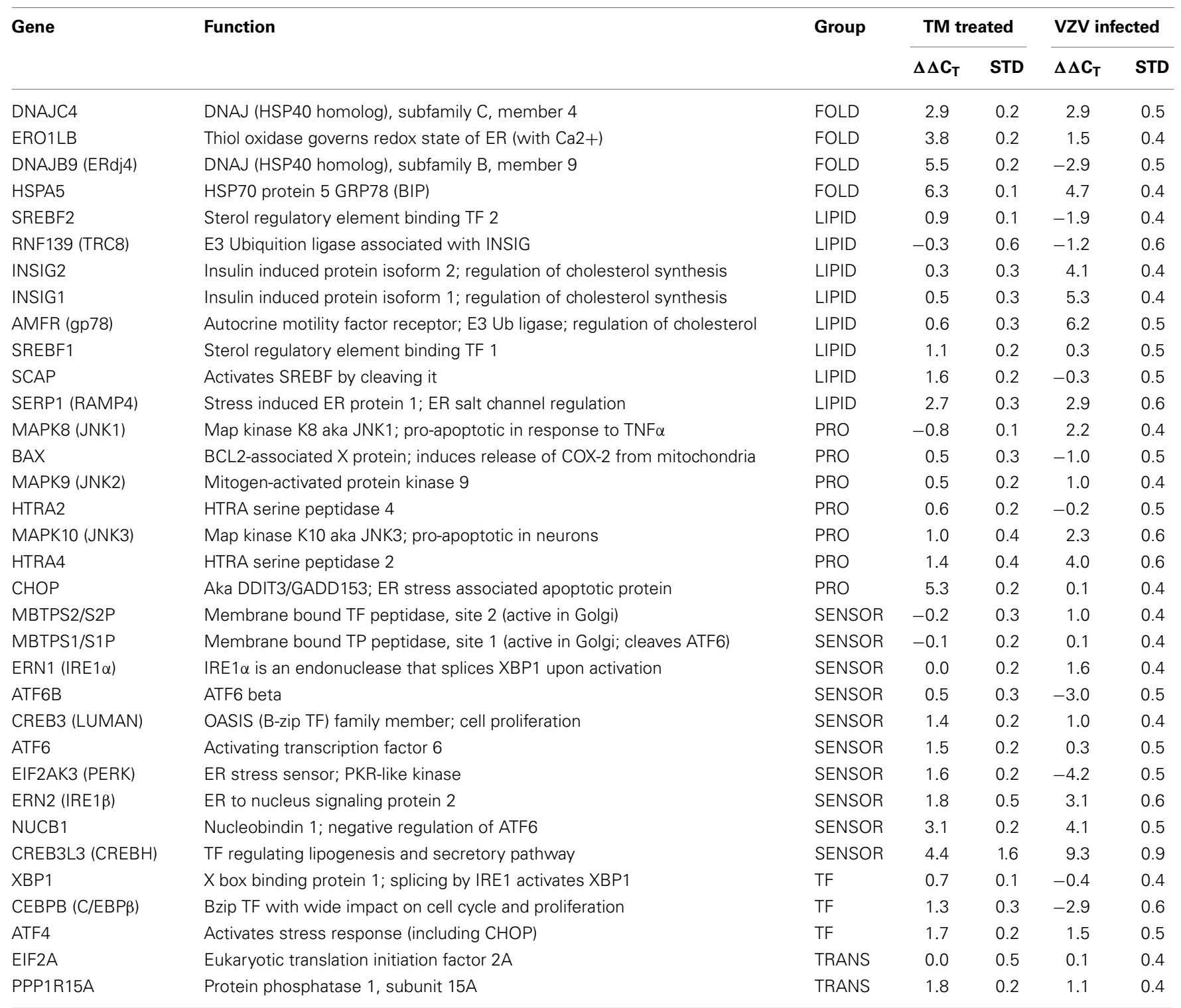

Human fibroblast cells (MRC-5) were grown on glass coverslips in tissue culture plates then infected with VZV-32 infected MRC-5 cells or treated with tunicamycin (TM), a N-glycosylation inhibitor. At 72 hpi, RNA was extracted from the VZV-32 infected cultures. For the TM treated cultures, RNA was extracted at $24 \mathrm{~h}$ posttreatment. RNA from the VZV-32 infected, TM treated and uninfected cell cultures was then converted to cDNA which was applied to UPR specific PCR arrays (SA Biosciences) and real time PCR was carried out on an ABI 7000 PCR instrument The resulting CT values were then normalized ( $\triangle C_{T}$ ) by housekeeping genes in the plate and then differences $\left(\Delta \triangle C_{T}\right)$ between the uninfected and infected or tunicamycin treated values were computed and averaged. Abbreviations: anti-apoptotic (ANTI), ER associated degradation (ERAD), protein folding chaperones (FOLD), lipid and fat metabolism (LIPID), pro-apoptotic (PRO), ER stress sensor proteins (SENSOR), other transcription factors (TF) and protein translation associated proteins (TRANS). Error estimates correspond to standard deviation (STD).

\section{VZV INFECTION SIGNIFICANTLY UPREGULATED THE TRANSCRIPTION FACTOR CREBH}

The SENSOR grouping includes the best known ER stress sensors: PERK, IRE1 $\alpha$ and ATF6 but also two CREB proteins (CREB3/LUMAN and CREBH) as well as primers to the Golgi resident proteases $S 1 P$ and $S 2 P$ that activate AT6 and the CREB proteins by cleavage (Ye et al., 2000; Asada et al., 2011). Included in the group are lesser known transcripts including IRE1 $\beta$, ATF6 $\beta$, and NUCB1.
CREBH, the cAMP responsive element binding protein $\mathrm{H}$, is an ER anchored transcription factor implicated in nutrient metabolism and the proinflammatory response. VZV infected cells displayed more transcripts of $C R E B H$ and fewer of $A T F 6 \beta$ and PERK (all with $p<0.001$ ) than in TM treated cells (Figure 3A). TM treatment generally upregulated all ER sensor transcripts with $C R E B H$ the most upregulated. CREBH transcription has previously been described as upregulated in hepatocytes and has been associated with lipid synthesis and acute phase 


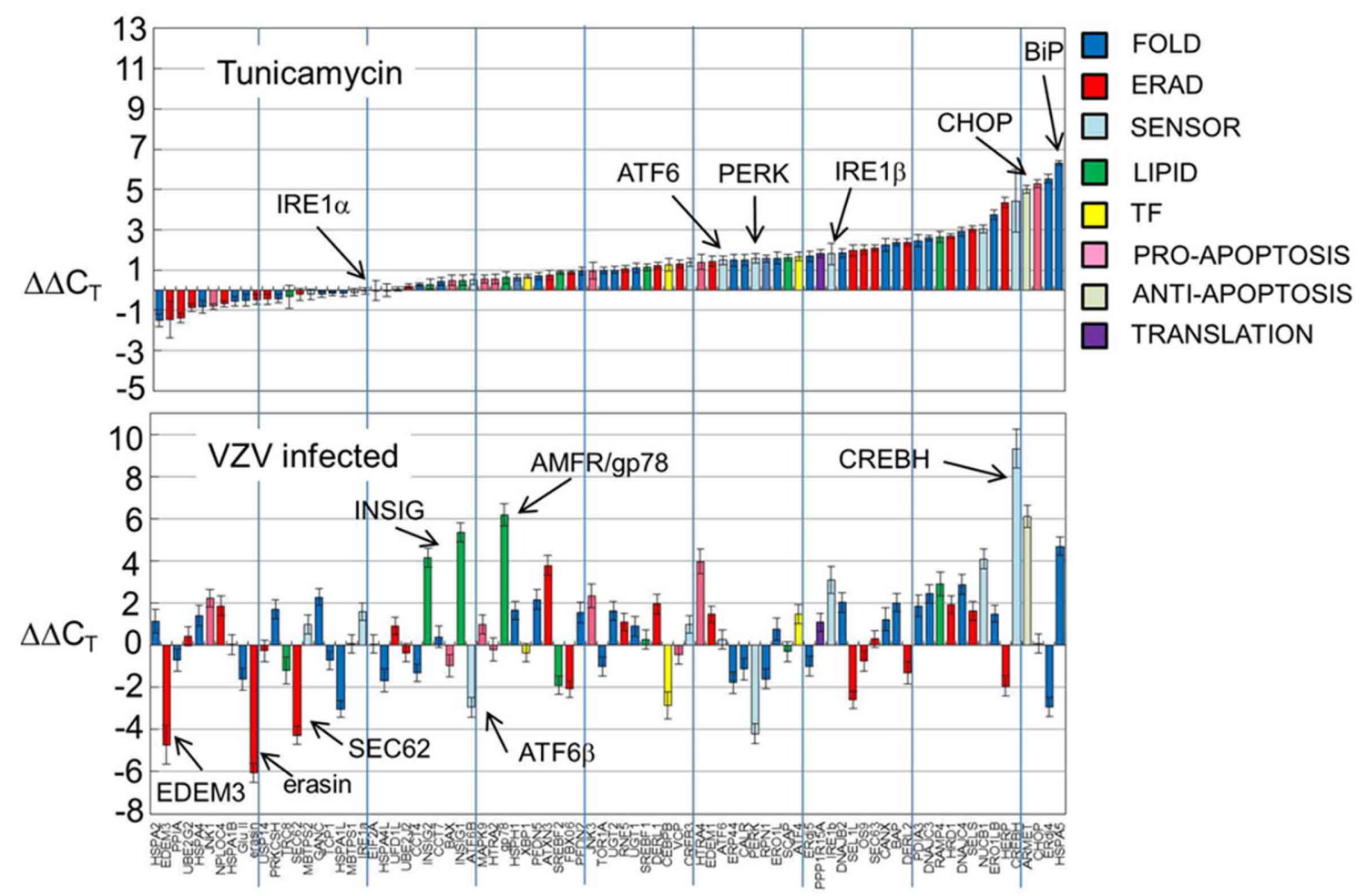

FIGURE 2 | UPR gene transcription was significantly different in VZV infected cells vs. either uninfected cells or tunicamycin treated cells. Human fibroblast cells (MRC-5) were grown in tissue culture plates then infected with VZV-32 infected MRC-5 cells or treated with tunicamycin (TM), a N-glycosylation inhibitor. At 72 hpi, RNA was extracted from the VZV-32 infected cultures. For the TM treated cultures, RNA was extracted at $24 \mathrm{~h}$ post-treatment. RNA from the VZV-32 infected, TM treated and uninfected cell cultures was then converted to CDNA, which was applied to UPR specific PCR arrays (SA Biosciences); real time PCR was carried out on an $\mathrm{ABI} 7000 \mathrm{PCR}$ instrument. The resulting $C_{T}$ values were then normalized $\left(\Delta \mathrm{C}_{\mathrm{T}}\right)$ by the housekeeping genes of the plate and differences $\left(\Delta \Delta \mathrm{C}_{\mathrm{T}}\right)$ between the uninfected and infected or tunicamycin treated values were computed and averaged. Graphs of the resulting values show that tunicamycin treatment, a classical ER stressor, resulted in upregulation of 66 of the 84 UPR genes with known folding chaperones such as BiP (in blue). Also upregulated was the pro-apoptotic factor $C H O P$. By contrast, only 43 of the UPR genes were upregulated in VZV infected cells although several, such as $C R E B H$, were more upregulated than in tunicamycin treated samples. Error bars correspond to standard deviation when averaging. transcription in T-cells (Zhang et al., 2006, 2012). More recently, $\mathrm{CREBH}$ as a transcription factor has been described as increasing the capacity of the secretory pathway (Barbosa et al., 2013). ATF $6 \beta$ and ATF $6 \alpha$ share similar structures but differ in function. In particular, $A T F 6 \beta$ has been reported to inhibit transcription of $A T F 6 \alpha$ one of the primary ER stress sensors (Thuerauf et al., 2007).

In order to confirm the results of the UPR specific PCR array, we carried out qPCR measurements using primers to $C R E B H$ and PERK (Figure 3B) in TM treated cells and at several timepoints in VZV infected cells. Those measurements confirm the upregulation of $C R E B H$ by TM treatment but particularly in VZV infected cells $(p<0.01)$. However, the downregulation of PERK in VZV infected cells was not confirmed.

\section{VZV INFECTED CELLS EXHIBITED UNEVEN FOLD GENE TRANSCRIPTION}

Within the FOLD group, the largest, there are 32 wells with primers to eight HSP-70 homologs including HSPA5/BiP and SIL1/BaP; five DNAJ HSP-40 homologs including DNAJB9/ERdj4 and DNAJC10/ERdj5; twelve wells contain primers to transcripts encoding ER lumen folding components including
CALR and CANX; three components of the folding chaperonin complex and finally four components in the ER membrane including RPN1 and SEC63. Many of these transcripts encode proteins which assist secretory protein folding but also sense misfolded proteins in the ER (Schroder, 2008). For example, DNAJC10/ERdj5 is a disulfide reductase that associates with ERAD component EDEM (Hagiwara et al., 2011).

VZV infected cells exhibited very uneven transcription of folding chaperones (FOLD) while TM treatment robustly upregulated transcription of these chaperones particularly $B i P$ (Figure 4A). Measurements with the UPR specific PCR array showed VZV infected cells upregulated BiP while downregulating DNAJB9/ERdj4 and HSPA1L. In order to reassess these observations, we carried out qPCR measurements of BiP and DNAJB9/ERDj4 using primers specific to those transcripts (Figure 4B) and found that neither the upregulation of $B i P$ nor downregulation of DNAJB9/ERDj4 was confirmed. Rather the qPCR results found $B i P$ to be moderately downregulated as the infection progressed to more cells $(p<0.05)$. However, we also reassessed the regulation of the ER-co-chaperone 


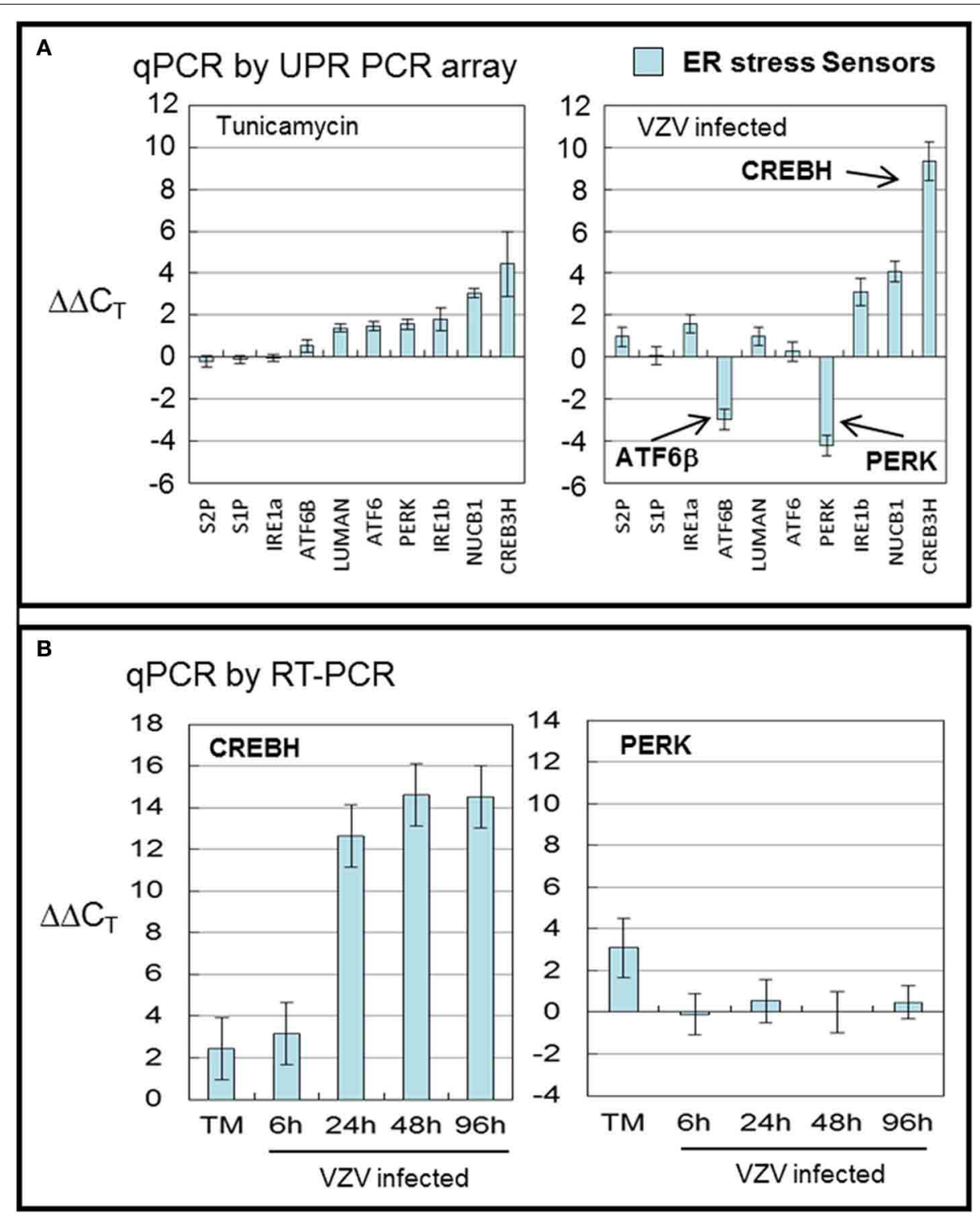

FIGURE 3 | VZV infection significantly upregulated the transcription factor CREBH. Human fibroblast cells (MRC-5) were grown in tissue culture plates then infected with VZV-32 infected MRC- 5 cells or treated with tunicamycin (TM), a N-glycosylation inhibitor. At 72 hpi, RNA was processed as described in legend to Figure 2. All gene transcription measurements were graphed for tunicamycin treated and VZV infected cell samples. (A) By measurements using the UPR specific PCR array, VZV infected cells showed significant upregulation of CREBH with downregulation of PERK and ATF6 $\beta$. Tunicamycin treatment upregulated to a lesser extent all stress SENSORs. (B) To assess some of the measurements by the UPR array, cDNA from VZV infected and tunicamycin treated cells was submitted for real-time (RT-) PCR using primers specific to CREBH and PERK (see Methods section for primer information). Error bars correspond to standard deviation when averaging.
DNAJC10/ERdj5 and found a correlation with the UPR-specific array (data not shown).

\section{VZV INFECTED CELLS SIGNIFICANTLY DOWNREGULATED ERAD GENE TRANSCRIPTION}

There are 21 ERAD associated wells that amplify a number of known transcripts that code for proteins that are involved in the degradation of misfolded proteins in the ER through a number of steps: recognition of misfolding (OS9, PPIA and SELS along with a number of FOLD transcripts), trimming of mannose residues prior to recognition by E3 ubiquitin ligases (EDEM1 and EDEM3), recognition of misfolded proteins by E3 ubiquition ligases (DERL3/HRD1, DERL2, DERL1, HERP, RNF5, and associated factors SEL1L and FBX06), exportation to the cytosolic side of the ER membrane (SEC62) where the VCP/p97 complex poly-ubiquitinates protein substrates before extracting/clipping the protein from the membrane to be ultimately degraded in the cytosol by the proteasome (Schroder, 2008; Merulla et al., 2013). The VCP/p97 complex includes its cofactors UFD1L and NPLOC4 and regulators ATAXIN3 and ARMET/erasin as well as the E2 ubiquitin-conjugators UBE2J2 and UBE2G2 (Ballar et al., 2011). 


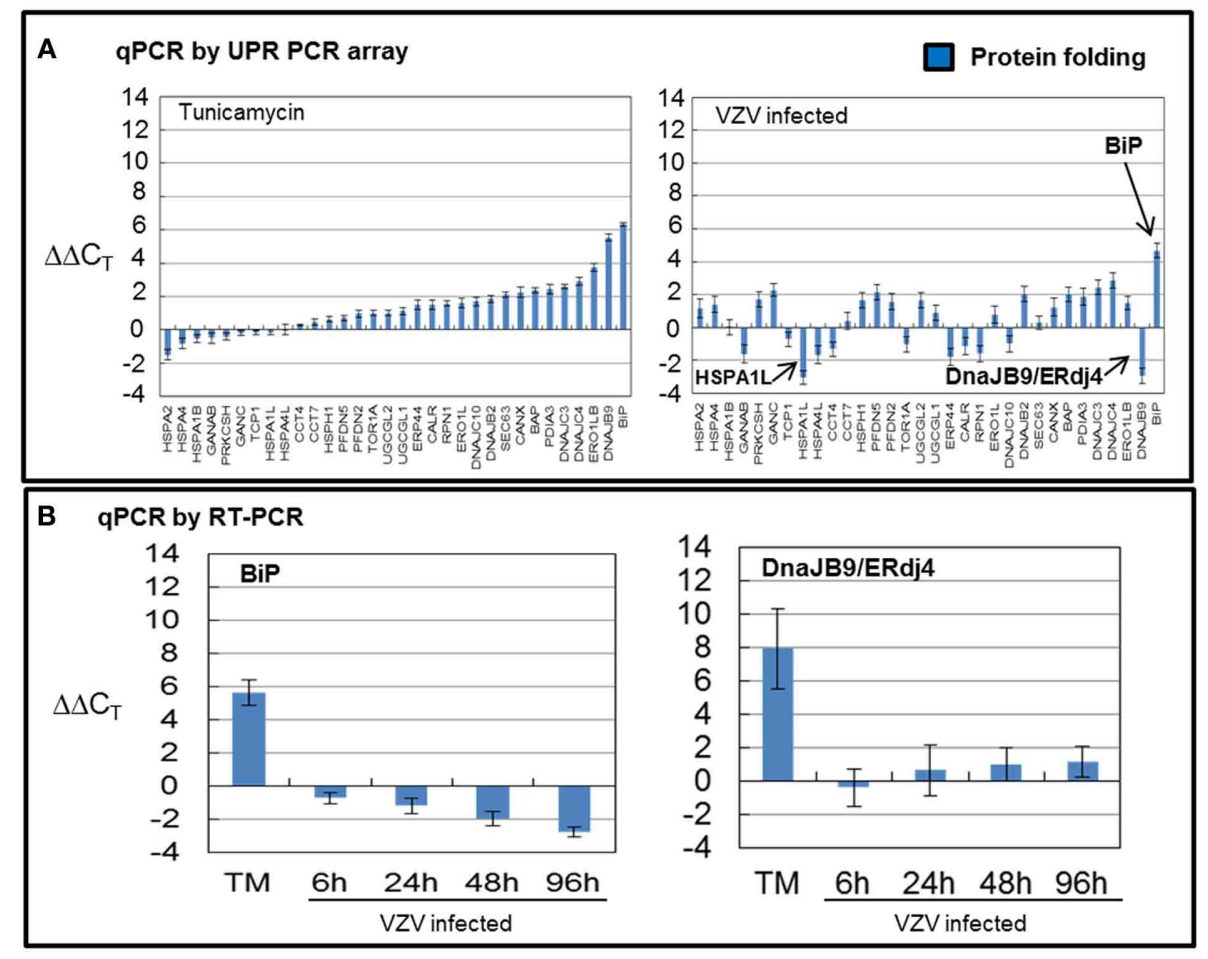

FIGURE 4 | VZV infected cells exhibited uneven transcription of protein folding genes. Human fibroblast cells (MRC-5) were grown in tissue culture plates then infected with VZV-32 infected MRC-5 cells or treated with tunicamycin (TM), a N-glycosylation inhibitor. At 72 hpi, RNA was processed as described in legend to Figure 2. All gene transcription measurements were graphed for tunicamycin treated and VZV infected cell samples. (A) Using the UPR specific PCR array, tunicamycin treated cells exhibited significant upregulation of transcripts of FOLD chaperones while VZV infected cells exhibited a much more uneven pattern of up or down regulation of FOLD transcripts. In particular, ERdj4/DNAJB9 and HSPA1L were downregulated with only BiP showing upregulation. (B) To assess some of the measurements by the UPR array, cDNA from VZV infected and tunicamycin treated cells was submitted for real-time (RT-) PCR, using primers specific to BiP and ERdj4/DNAJB9 (see Methods section for primer information). Error bars correspond to standard deviation when averaging.
Finally, there is a cytosolic protease, USP14, included in this grouping.

While TM treatment showed almost complete upregulation of ERAD transcripts particularly HERP (Figure 5A), VZV infection showed considerable downregulation of ERAD transcript (Figure 5A) where EDEM3, UBXN4/erasin and SEC62 were downregulated. However, ATAXIN3 was upregulated in VZV infected cells. Both erasin and ATAXIN3 are regulators, positive and negative, respectively, of VCP/p97 (Lim et al., 2009; Liu and Ye, 2012). As noted above, VCP/p97 forms the protein complex in the ER membrane on the cytosolic side that poly-ubiqininates ERAD substrates that are then released into the cytosol to be degraded by the proteasome (Ballar et al., 2011). Downregulation of VCP/p97 via its regulators appeared to reduce ERAD in VZV infected cells. All observed differences were significant with $p<0.001$. Again, in order to reassess two of the more striking observations from the UPR specific PCR array, we carried out $\mathrm{qPCR}$ measurements using primers to UBXN4/erasin and ATAXIN-3 (Figure 5B). These measurements showed UBXN4/erasin to be modestly downregulated in VZV infected cells while ATAXIN-3 was essentially unchanged.

\section{VZV INFECTED CELLS UPREGULATED TRANSCRIPTION OF CHOLESTEROL SYNTHESIS REGULATOR INSIG}

Transcripts associated with lipid synthesis and metabolism such as RAMP4 showed similar transcription in both VZV infected and TM treated cells but VZV infected cells, in particular, showed increased transcription of cholesterol synthesis regulators $A M F R / g p 78$ and INSIG (Figure 6A). AMFR/gp78 is an E3 ubiquitin ligase and INSIG is an insulin signaling factor (Flury et al., 2005; Chen et al., 2012). Both are localized to the ER membrane and when activated function together to degrade HMG COA reductase, a cholesterol synthesis enzyme (Jo et al., 2011; Tsai et al., 2012).

In order to reassess the upregulation of $A M F R / g p 78$ and INSIG, we carried out qPCR measurements using primers to each transcript (Figure 6B). Of note, INSIG was upregulated in VZV infected cells at early timepoints in agreement with the UPR specific array, while $A M F R / g p 78$ was not increased. Of note, greater transcription of INSIG may lead to reduced cholesterol synthesis in VZV infected cells with the consequence of a more fluid ER in those cells. Cholesterol acts as a stabilizing agent in lipid membranes by supporting adjacent lipid head groups and reducing disorder of the lipid 


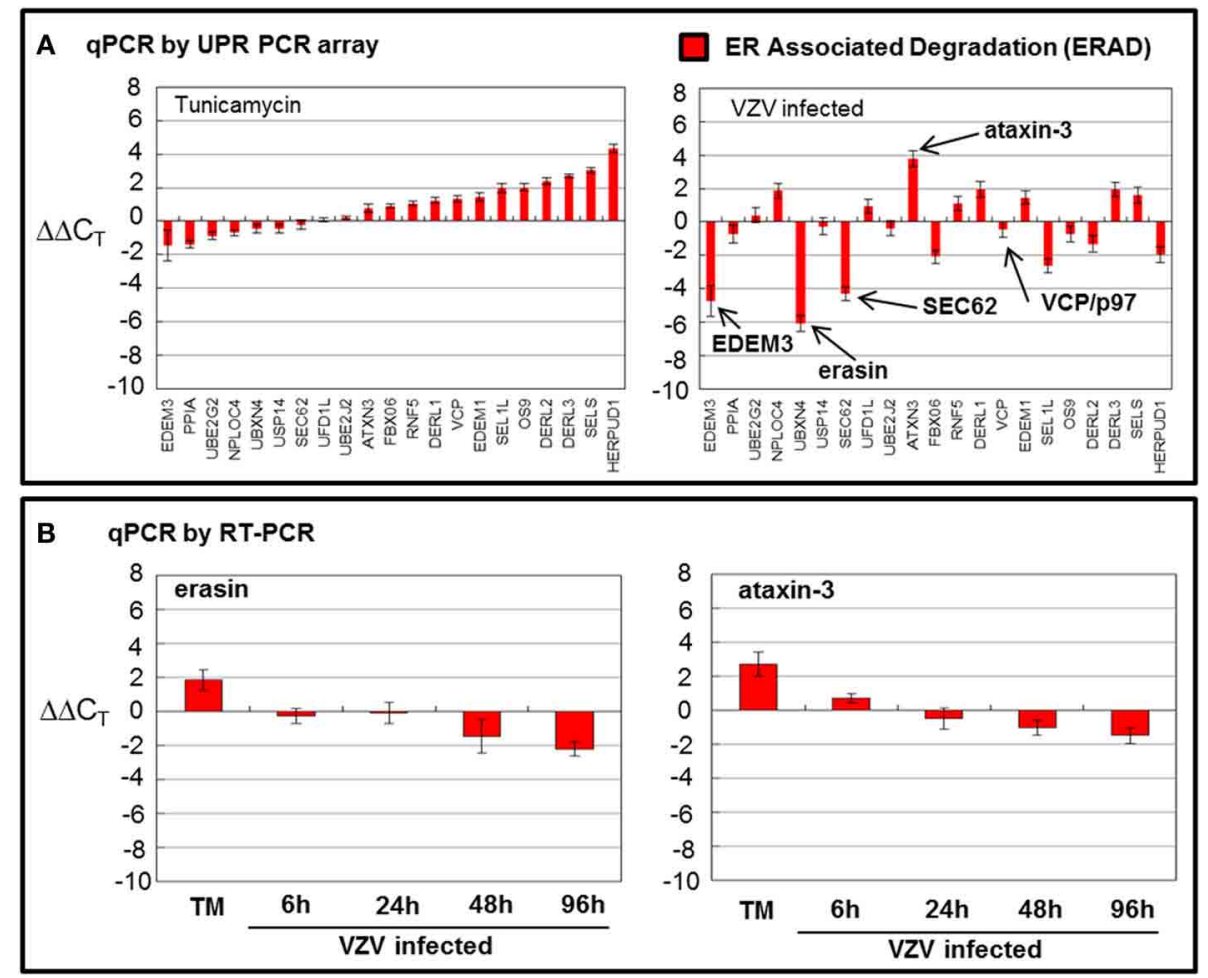

FIGURE 5 | VZV infection moderately downregulated ER associated degradation genes. Human fibroblast cells (MRC-5) were grown in tissue culture plates then infected with VZV-32 infected MRC-5 cells or treated with tunicamycin (TM), a N-glycosylation inhibitor. At 72 hpi, RNA was processed as described in the legend to Figure 2. All gene transcription measurements were graphed for tunicamycin treated and VZV infected cell samples. (A) By measurements using the UPR specific
PCR array, VZV infected cells showed significant downregulation of several elements of the ERAD pathway: EDEM3, ERASIN, and SEC62. Tunicamycin treatment, in contrast, upregulated most of the ERAD transcripts. (B) In order to assess two of the ERAD transcript measurements by the UPR specific PCR array, RT-PCR was carried out on cDNA from uninfected, tunicamycin treated and VZV infected cells, using primers to UBXN4/erasin and ataxin-3. hydrocarbon chains internal to the bilayer (Mouritsen and Zuckermann, 2004). All observed differences were significant with $p<0.001$.

\section{VZV INFECTED CELLS DOWNREGULATED THE TRANSCRIPTION FACTOR C/EBPb AND DISPLAYED DIFFERENTIAL TRANSCRIPTION OF APOPTOTIC TRANSCRIPTS}

Transcription of cellular transcription factor $C / E B P \beta$ was significantly downregulated $(p<0.001)$ in VZV infected cells as compared to the value in TM treated cells (Figure 7A) C/EBP $\beta$ is a transcription factor with a large effect on cellular proliferation (Tang and Lane, 2000). Downregulation of this factor may put VZV infected cells into a non-proliferative state. Transcription of apoptotic genes differed considerably between VZV infected cells and TM treated cells. TM treated cells exhibited much higher $C H O P$ transcription than VZV infected cells while VZV infected cells showed a greater number of transcripts associated with cellular apoptosis such as HTRA4 and the MAP kinases JNK1 and JNK3 (Figure 7B). Finally there was no difference between the levels of two protein translation associated transcripts in VZV infected cells vs. TM treated cells (Figure 7C).

\section{TRANSFECTION OF VZV gE UPREGULATED TRANSCRIPTION OF CREBH AND BiP WHILE TRANSFECTION OF VZV IE62 DID NOT}

In 2011, we found that transfecting cells with VZV glycoprotein genes led to increased autophagosome production and inflation of the ER. Transfection with VZV IE62 led to neither increased autophagosomes nor a larger ER. Therefore, we measured by $\mathrm{qPCR}$ whether $\mathrm{CREBH}$ and $\mathrm{BiP}$ transcription was increased by transfection of a glycoprotein vs. a nonglycoprotein that is also the major transactivator encoded by VZV. Transfection with a plasmid encoding VZV gE under the CMV immediate early promoter led to approximately $10 \%$ of transfected cells (Figure 8A1) while transfection with VZV IE62 also under the CMV immediate early promoter led to a larger number, approximately $40 \%$, of transfected cells (Figure 8A2). Even though a low fraction of cells were transfected with VZV gE, increased transcription of $C R E B H$ and $B i P$ were observed in those cells (Figures 8B1,B2) whereas not in cells transfected with VZV IE62 even though many more cells were transfected in those samples $(p<0.01)$. We therefore conclude that expression of a single VZV glycoprotein gene in cells is sufficient to activate the CREBH arm of the UPR. 


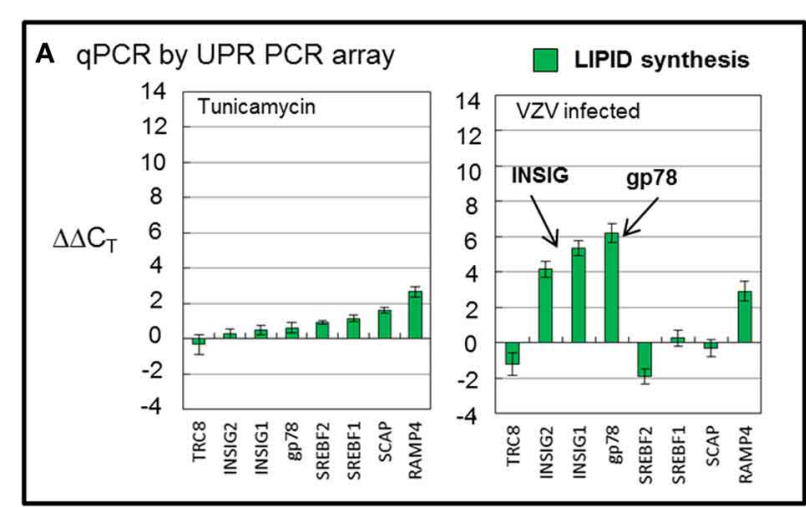

B qPCR by RT-PCR

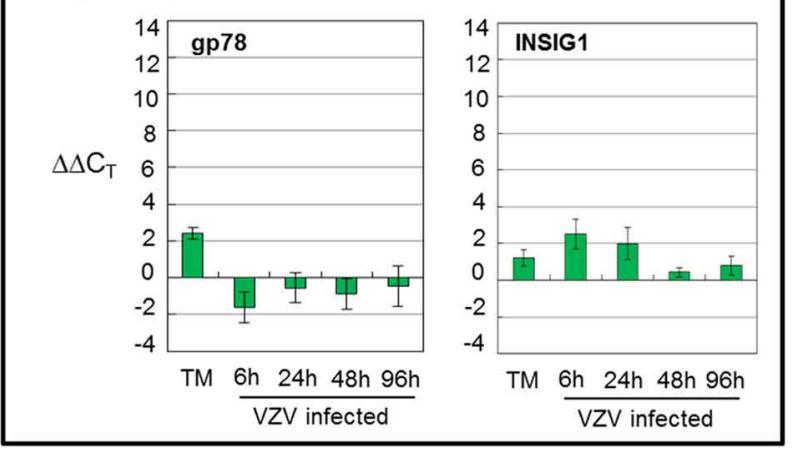

FIGURE 6 | VZV infection significantly upregulated the cholesterol synthesis associated transcript INSIG. Human fibroblast cells (MRC-5) were grown in tissue culture plates then infected with VZV-32 infected MRC-5 cells or treated with tunicamycin (TM), a N-glycosylation inhibitor. At $72 \mathrm{hpi}, \mathrm{RNA}$ was processed as described in the legend to Figure 2. (A) Transcripts associated with lipid synthesis and metabolism where both VZV infected cells and tunicamycin cells showed similar transcription of RAMP4; VZV infected cells in particular showed more transcription of cholesterol synthesis regulator INSIG. (B) In order to assess two of the lipid transcript measurements by the UPR specific PCR array, RT-PCR was carried out on cDNA from uninfected, tunicamycin treated and VZV infected cells using primers to AMFR/gp78 and INSIG1.

\section{DISCUSSION}

We have previously documented that VZV infection induces an autophagic response in infected cells. The basic observation of this report is that VZV infected cells differentially activate the UPR to ER stress as compared to tunicamycin treated cells. The most straightforward explanation for this observation is that tunicamycin treatment produces many misfolded glycoproteins while VZV infection produces an overabundance of normally folded glycoproteins. The elements of the UPR activated in each situation would likely differ. As compared to the positive control of tunicamycin treated cells, VZV infected cells showed increased transcription of a gene associated with decreased cholesterol synthesis as well as increased transcription of the ER stress sensor and transcription factor, $C R E B H$. At the same time, VZV infected cells showed decreased transcription of genes associated with ERAD and apoptosis. We hypothesize that this transcriptional profile is compatible with the infected cell attempting to accommodate the influx of viral glycoproteins by greatly increasing the

capacity of the ER. For example, increased transcription of AMFR (gp78) and INSIG is associated with a decrease in cholesterol synthesis via degradation of HMG-CoA reductase, an enzyme necessary for cholesterol synthesis (Jo et al., 2011; Tsai et al., 2012). Decreased cholesterol content would increase the lability of the ER membrane and facilitate expansion of the ER (Mouritsen and Zuckermann, 2004).

We also found that some differences in transcription between tunicamycin treated cells vs. VZV infected cells as measured by the UPR specific PCR array could not be confirmed by qPCR, using individual primers selected by our laboratory. The reason behind these discrepancies is unclear but may center around two possibilities: (i) The choice of primers in the PCR array vs. those used in the qPCR measurements or (ii) the asynchronous nature of VZV infection. In general, there was better agreement between tunicamycin treated values as measured by the UPR-specific PCR 


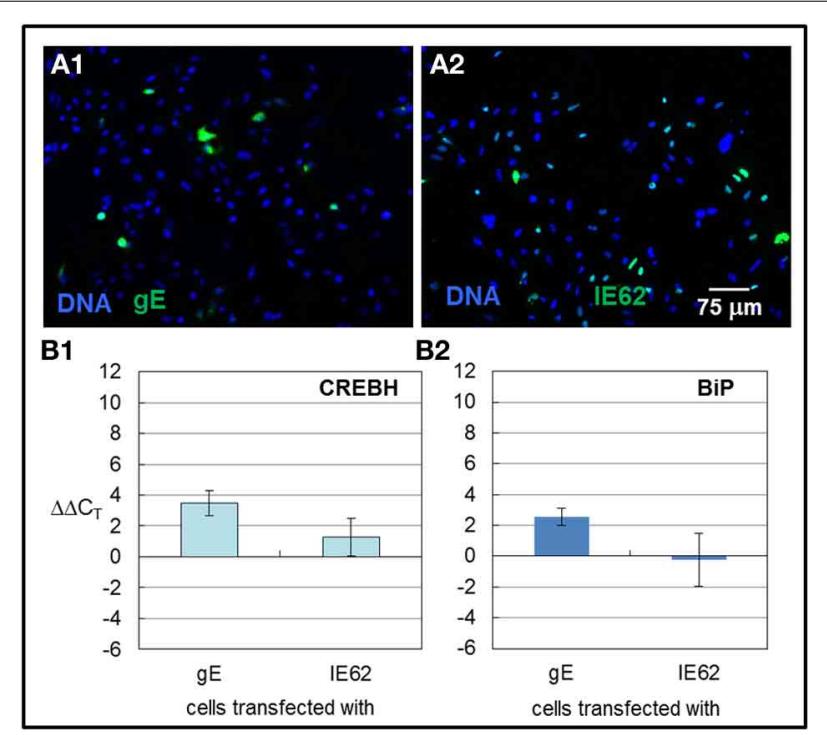

FIGURE 8 | CREBH and BiP transcription were upregulated in cells transfected with VZV gE but not VZV IE62. HeLa cells were grown in six well culture plates with or without glass coverslips and subsequently transfected with plasmids encoding the VZV gE glycoprotein or a non-glycosylated VZV IE62 protein, using either Lipofectamine 2000 or ExtremeGene HP transfection reagents. $6 \mathrm{~h}$ after the transfection reagent and plasmid were applied to the cells, the medium was replaced with fresh medium. Some monolayers were processed for microscopy while others were harvested for RNA extraction. The extracted RNA was converted to CDNA and RT-PCR was performed using primers against $C R E B H$ and BiP. $(\mathbf{A} \mathbf{1}, \mathbf{A 2})$ Representative images of cells transfected with VZV gE (A1) or VZV IE62 (A2). (B1,B2) RT-PCR values were normalized to GAPDH and then differences to values measured for cells that were only treated with transfection reagent alone were computed.

array and individual qPCR assays. The biggest differences were observed in values measured from VZV infected cells. The latter scenario suggests that asynchronous VZV infection may play a role; for example, the input virus is always extremely low, such that some cells within a monolayer will remain uninfected even at $72 \mathrm{hpi}$. This same scenario may explain why we have observed similar unexpected differences in experiments to measure protein expression, for example, BiP. Because of increased VZV-induced autophagy, we predicted increased BiP production in infected cells. However, we have observed variable changes in BiP protein expression following VZV infection. Nevertheless, the main conclusions of this report were confirmed by both assays, namely, the significant upregulation of $\mathrm{CREBH}$ as well as the more modest upregulation of the cholesterol regulator INSIG.

A key question is whether the infected cell is responding to abundant viral glycoprotein expression through normal mechanisms or alternatively, does the virus encode its own proteins which manipulate the UPR. Recently, Burnett et al found that HSV ICP0 transactivated elements of the UPR and in turn was transactivated by the UPR itself via an ERSE promoter element in the HSV ICP0 gene (Burnett et al., 2012). Similarly, both the human and murine strains of the beta herpesvirus cytomegalovirus (CMV) encode proteins that manipulate the UPR—proteins that the VZV genome does not encode (Isler et al.,
2005; Xuan et al., 2009; Qian et al., 2012; Stahl et al., 2013). VZV does encode a homolog of HSV ICP0-ORF61, but its promoter region does not appear to have any of the known UPR promoter elements: ERSE, ERSE-II, and UPRE based on bioinformatics searches (data not shown). It would be interesting to test VZV ORF61 against a luciferase reporter construct containing the $\mathrm{BiP}$ promoter element in future experiments.

In further support of our hypothesis that abundant expression of VZV glycoproteins contributes to the activation of the UPR in a specific way that leads to an enlarged ER and increased autophagosome production, we found that transfection of the VZV gE gene led to increased $C R E B H$ and BiP transcription. We observed abundant VZV gE protein in the ER/Golgi after transfection. In contrast, transfection with VZV IE62, a nonglycosylated viral protein, did not lead to increased transcription of either transcript. Obviously, the IE62 protein never enters the ER/Golgi. These results confirm and expand our 2011 report that transfection with VZV glycoprotein genes resulted in increased ER size and increased autophagosome production. The UPR is known to upregulate autophagy (Yorimitsu et al., 2006).

In summary, even though both tunicamycin treatment and VZV infection induced an UPR, the profiles of UPR related genes were different after the two analyses. The UPR in VZV infected cells exhibited greatly increased $C R E B H$ and cholesterol synthesis regulation transcription and diminished ERAD transcription. The transcription patterns appeared to correlate with increasing ER capacity secondary to increasing viral glycoprotein synthesis in the infected cell. Of importance, the CREBH data were totally unexpected, based on all prior VZV research, and would never have been uncovered in the absence of the UPR array data described in this report.

\section{ACKNOWLEDGMENTS}

Instruments used in the above analyses were maintained by the University of Iowa Central Microscopy Research Facility and the Institute for Human Genetics. Research was supported by NIH grant AI89716.

\section{REFERENCES}

Arvin, A. M. (1987). "Clinical manifestations of varicella and herpes zoster and the immune response to varicella-zoster virus," in The Natural History of Varicella-Zoster Virus, ed R. Hyman (New York, NY: CRC Press), $17-130$.

Arvin, A. M., Moffat, J. F., Sommer, M., Oliver, S., Che, X., Vleck, S., et al. (2010). Varicella-zoster virus $\mathrm{T}$ cell tropism and the pathogenesis of skin infection. Curr. Top. Microbiol. Immunol. 342, 189-209. doi: 10.1007/82_2010_29

Asada, R., Kanemoto, S., Kondo, S., Saito, A., and Imaizumi, K. (2011). The signalling from endoplasmic reticulum-resident bZIP transcription factors involved in diverse cellular physiology. J. Biochem. 149, 507-518. doi: $10.1093 / \mathrm{jb} / \mathrm{mvr} 041$

Ballar, P., Pabuccuoglu, A., and Kose, F. A. (2011). Different p97/VCP complexes function in retrotranslocation step of mammalian ER-associated degradation (ERAD). Int. J. Biochem. Cell Biol. 43, 613-621. doi: 10.1016/j.biocel.2010.12.021

Barbosa, S., Fasanella, G., Carreira, S., Llarena, M., Fox, R., Barreca, C., et al. (2013). An orchestrated program regulating secretory pathway genes and cargos by the transmembrane transcription factor CREB-H. Traffic 14, 382-398. doi: $10.1111 /$ tra. 12038

Buckingham, E. M., Carpenter, J. E., Jackson, W., and Grose, C. (2014). Autophagy and the effects of its inhibition on varicella-zoster virus glycoprotein biosynthesis and infectivity. J. Virol. 88, 890-902. doi: 10.1128/JVI.02646-13 
Burnett, H. F., Audas, T. E., Liang, G., and Lu, R. R. (2012). Herpes simplex virus-1 disarms the unfolded protein response in the early stages of infection. Cell Stress Chaperones 17, 473-483. doi: 10.1007/s12192-012-0324-8

Carpenter, J. E., Hutchinson, J. A., Jackson, W., and Grose, C. (2008). Egress of light particles among filopodia on the surface of varicella-zoster virus-infected cells. J. Virol. 82, 2821-2835. doi: 10.1128/JVI.01821-07

Carpenter, J. E., Jackson, W., Benetti, L., and Grose, C. (2011). Autophagosome formation during varicella-zoster virus infection following endoplasmic reticulum stress and the unfolded protein response. J. Virol. 85, 9414-9424. doi: 10.1128/JVI.00281-11

Carpenter, J. E., Jackson, W., De Souza, G. A., Haarr, L., and Grose, C. (2010). Insulin-degrading enzyme binds to the nonglycosylated precursor of varicellazoster virus $\mathrm{gE}$ protein found in the endoplasmic reticulum. J. Virol. 84, 847-855. doi: 10.1128/JVI.01801-09

Chen, Z., Du, S., and Fang, S. (2012). gp78: a multifaceted ubiquitin ligase that integrates a unique protein degradation pathway from the endoplasmic reticulum. Curr. Protein Pept. Sci. 13, 414-424. doi: 10.2174/138920312802 430590

Choo, P. W., Donahue, J. G., Manson, J. E., and Platt, R. (1995). The epidemiology of varicella and its complications. J. Infect. Dis. 172, 706-712. doi: 10.1093/infdis/172.3.706

Davison, A. J. (2010). Herpesvirus systematics. Vet. Microbiol. 143, 52-69. doi: 10.1016/j.vetmic.2010.02.014

Davison, A. J., and Scott, J. E. (1986). The complete DNA sequence of varicella-zoster virus. J. Gen. Virol. 67, 1759-1816. doi: 10.1099/0022-1317-679-1759

Duus, K. M., Hatfield, C., and Grose, C. (1995). Cell surface expression and fusion by the varicella-zoster virus $\mathrm{gH}: \mathrm{gL}$ glycoprotein complex: analysis by laser scanning confocal microscopy. Virology 210, 429-440. doi: 10.1006/viro. 1995.1359

Flury, I., Garza, R., Shearer, A., Rosen, J., Cronin, S., and Hampton, R. Y. (2005). INSIG: a broadly conserved transmembrane chaperone for sterolsensing domain proteins. EMBO J. 24, 3917-3926. doi: 10.1038/sj.emboj. 7600855

Gilden, D. H., Cohrs, R. J., and Mahalingam, R. (2003). Clinical and molecular pathogenesis of varicella virus infection. Viral Immunol. 16, 243-258. doi: $10.1089 / 088282403322396073$

Grose, C. (1980). The synthesis of glycoproteins in human melanoma cells infected with varicella-zoster virus. Virology 101, 1-9. doi: 10.1016/00426822(80)90478-X

Grose, C. (1981). Variation on a theme by fenner: the pathogenesis of chickenpox. Pediatrics 68, 735-737.

Grose, C., and Brunel, P. A. (1978). Varicella-zoster virus: isolation and propagation in human melanoma cells at 36 and 32 degrees C. Infect. Immun. 19, 199-203.

Grose, C., Friedrichs, W. E., and Smith, G. C. (1983). Purification and molecular anatomy of the varicella-zoster virion. Biken J. 26, 1-15.

Hagiwara, M., Maegawa, K., Suzuki, M., Ushioda, R., Araki, K., Matsumoto, Y., et al. (2011). Structural basis of an ERAD pathway mediated by the ER-resident protein disulfide reductase ERdj5. Mol. Cell 41, 432-444. doi: 10.1016/j.molcel.2011.01.021

Hope-Simpson, R. E. (1965). The nature of herpes zoster: a long-term study and a new hypothesis. Proc. R. Soc. Med. 58, 9-20.

Isler, J. A., Skalet, A. H., and Alwine, J. C. (2005). Human cytomegalovirus infection activates and regulates the unfolded protein response. J. Virol. 79, 6890-6899. doi: 10.1128/JVI.79.11.6890-6899.2005

Jacobsen, L. B., Calvin, S. A., Colvin, K. E., and Wright, M. (2004). FuGENE 6 transfection reagent: the gentle power. Methods 33, 104-112. doi: 10.1016/j.ymeth.2003.11.002

Jo, Y., Lee, P. C., Sguigna, P. V., and Debose-Boyd, R. A. (2011). Sterol-induced degradation of HMG CoA reductase depends on interplay of two Insigs and two ubiquitin ligases, gp78 and Trc8. Proc. Natl. Acad. Sci. U.S.A. 108, 20503-20508. doi: 10.1073/pnas.1112831108

Kinchington, P. R., Hougland, J. K., Arvin, A. M., Ruyechan, W. T., and Hay, J. (1992). The varicella-zoster virus immediate-early protein IE62 is a major component of virus particles. J. Virol. 66, 359-366.

Ku, C. C., Zerboni, L., Ito, H., Graham, B. S., Wallace, M., and Arvin, A. M. (2004). Varicella-zoster virus transfer to skin by T Cells and modulation of viral replication by epidermal cell interferon-alpha. J. Exp. Med. 200, 917-925. doi: 10.1084/jem.20040634
Lim, P. J., Danner, R., Liang, J., Doong, H., Harman, C., Srinivasan, D., et al. (2009). Ubiquilin and p97/VCP bind erasin, forming a complex involved in ERAD. J. Cell Biol. 187, 201-217. doi: 10.1083/jcb.200903024

Liu, Y., and Ye, Y. (2012). Roles of p97-associated deubiquitinases in protein quality control at the endoplasmic reticulum. Curr. Protein Pept. Sci. 13, 436-446. doi: $10.2174 / 138920312802430608$

Marin, M., Zhang, J. X., and Seward, J. F. (2011). Near elimination of varicella deaths in the US after implementation of the vaccination program. Pediatrics 128, 214-220. doi: 10.1542/peds.2010-3385

Merulla, J., Fasana, E., Solda, T., and Molinari, M. (2013). Specificity and regulation of the endoplasmic reticulum-associated degradation machinery. Traffic 14, 767-777. doi: 10.1111/tra.12068

Montalvo, E. A., Parmley, R. T., and Grose, C. (1985). Structural analysis of the varicella-zoster virus gp98-gp62 complex: posttranslational addition of $\mathrm{N}$-linked and O-linked oligosaccharide moieties. J. Virol. 53, 761-770.

Mouritsen, O. G., and Zuckermann, M. J. (2004). What's so special about cholesterol? Lipids 39, 1101-1113. doi: 10.1007/s11745-004-1336-x

Peters, G. A., Tyler, S. D., Grose, C., Severini, A., Gray, M. J., Upton, C., et al. (2006). A full-genome phylogenetic analysis of varicella-zoster virus reveals a novel origin of replication-based genotyping scheme and evidence of recombination between major circulating clades. J. Virol. 80, 9850-9860. doi: 10.1128/JVI.00715-06

Qian, Z., Xuan, B., Chapa, T. J., Gualberto, N., and Yu, D. (2012). Murine cytomegalovirus targets transcription factor ATF4 to exploit the unfoldedprotein response. J. Virol. 86, 6712-6723. doi: 10.1128/JVI.00200-12

Ross, A. H. (1962). Modification of chicken pox in family contacts by administration of gamma globulin. N. Engl. J. Med. 267, 369-376. doi: 10.1056/NEJM196208232670801

Sabnis, R. W., Deligeorgiev, T. G., Jachak, M. N., and Dalvi, T. S. (1997). DiOC6(3): a useful dye for staining the endoplasmic reticulum. Biotech. Histochem. 72, 253-258. doi: 10.3109/10520299709082249

Schroder, M. (2008). Endoplasmic reticulum stress responses. Cell. Mol. Life Sci. 65, 862-894. doi: 10.1007/s00018-007-7383-5

Seward, J. F., Marin, M., and Vazquez, M. (2008). Varicella vaccine effectiveness in the US vaccination program: a review. J. Infect. Dis. 197(Suppl. 2), S82-S89. doi: $10.1086 / 522145$

Stahl, S., Burkhart, J. M., Hinte, F., Tirosh, B., Mohr, H., Zahedi, R. P., et al. (2013). Cytomegalovirus downregulates IRE1 to repress the unfolded protein response. PLoS Pathog. 9:e1003544. doi: 10.1371/journal.ppat. 1003544

Takahashi, M. N., Jackson, W., Laird, D. T., Culp, T. D., Grose, C., Haynes, J. I., et al. (2009). Varicella-zoster virus infection induces autophagy in both cultured cells and human skin vesicles. J. Virol. 83, 5466-5476. doi: 10.1128/JVI. 02670-08

Tang, Q. Q., and Lane, M. D. (2000). Role of C/EBP homologous protein (CHOP$10)$ in the programmed activation of CCAAT/enhancer-binding protein-beta during adipogenesis. Proc. Natl. Acad. Sci. U.S.A. 97, 12446-12450. doi: $10.1073 /$ pnas. 220425597

Thuerauf, D. J., Marcinko, M., Belmont, P. J., and Glembotski, C. C. (2007). Effects of the isoform-specific characteristics of ATF6 alpha and ATF6 beta on endoplasmic reticulum stress response gene expression and cell viability. J. Biol. Chem. 282, 22865-22878. doi: 10.1074/jbc.M701 213200

Tsai, Y. C., Leichner, G. S., Pearce, M. M., Wilson, G. L., Wojcikiewicz, R. J., Roitelman, J., et al. (2012). Differential regulation of HMG-CoA reductase and Insig-1 by enzymes of the ubiquitin-proteasome system. Mol. Biol. Cell 23, 4484-4494. doi: 10.1091/mbc.E12-08-0631

Weigle, K. A., and Grose, C. (1984). Molecular dissection of the humoral immune response to individual varicella-zoster viral proteins during chickenpox, quiescence, reinfection, and reactivation. J. Infect. Dis. 149, 741-749. doi: 10.1093/infdis/149.5.741

Weller, T. H. (1983). Varicella and herpes zoster. Changing concepts of the natural history, control, and importance of a not-so-benign virus. N. Engl. J. Med. 309, 1434-1440. doi: 10.1056/NEJM198312083092306

Xuan, B., Qian, Z., Torigoi, E., and Yu, D. (2009). Human cytomegalovirus protein pUL38 induces ATF4 expression, inhibits persistent JNK phosphorylation, and suppresses endoplasmic reticulum stress-induced cell death. J. Virol. 83, 3463-3474. doi: 10.1128/JVI.02307-08 
Ye, J., Rawson, R. B., Komuro, R., Chen, X., Dave, U. P., Prywes, R., et al. (2000). ER stress induces cleavage of membrane-bound ATF6 by the same proteases that process SREBPs. Mol. Cell 6, 1355-1364. doi: 10.1016/S1097-2765(00) 00133-7

Yorimitsu, T., Nair, U., Yang, Z., and Klionsky, D. J. (2006). Endoplasmic reticulum stress triggers autophagy. J. Biol. Chem. 281, 30299-30304. doi: 10.1074/jbc.M607007200

Zhang, C., Wang, G., Zheng, Z., Maddipati, K. R., Zhang, X., Dyson, G., et al. (2012). Endoplasmic reticulum-tethered transcription factor cAMP responsive element-binding protein, hepatocyte specific, regulates hepatic lipogenesis, fatty acid oxidation, and lipolysis upon metabolic stress in mice. Hepatology 55, 1070-1082. doi: 10.1002/hep.24783

Zhang, K., Shen, X., Wu, J., Sakaki, K., Saunders, T., Rutkowski, D. T., et al. (2006). Endoplasmic reticulum stress activates cleavage of CREBH to induce a systemic inflammatory response. Cell 124, 587-599. doi: 10.1016/j.cell.2005. 11.040
Conflict of Interest Statement: The authors declare that the research was conducted in the absence of any commercial or financial relationships that could be construed as a potential conflict of interest.

Received: 14 March 2014; accepted: 11 June 2014; published online: 01 July 2014. Citation: Carpenter JE and Grose C (2014) Varicella-zoster virus glycoprotein expression differentially induces the unfolded protein response in infected cells. Front Microbiol. 5:322. doi: 10.3389/fmicb.2014.00322

This article was submitted to Virology, a section of the journal Frontiers in Microbiology.

Copyright (c) 2014 Carpenter and Grose. This is an open-access article distributed under the terms of the Creative Commons Attribution License (CC BY). The use, distribution or reproduction in other forums is permitted, provided the original author(s) or licensor are credited and that the original publication in this journal is cited, in accordance with accepted academic practice. No use, distribution or reproduction is permitted which does not comply with these terms. 